\title{
REVIEW
}

\section{The use of diaries in psychological recovery from intensive care}

Leanne M Aitken ${ }^{1,2^{*}}$, Janice Rattray ${ }^{3}$, Alastair Hull ${ }^{4}$, Justin A Kenardy ${ }^{5,6}$, Robyne Le Brocque ${ }^{5}$ and Amanda J Ullman ${ }^{1}$

\begin{abstract}
Intensive care patients frequently experience memory loss, nightmares, and delusional memories and some may develop symptoms of anxiety, depression, and post-traumatic stress. The use of diaries is emerging as a putative tool to 'fill the memory gaps' and promote psychological recovery. In this review, we critically analyze the available literature regarding the use and impact of diaries for intensive care patients specifically to examine the impact of diaries on intensive care patients' recovery. Diversity of practice in regard to the structure, content, and process elements of diaries for intensive care patients exists and emphasizes the lack of an underpinning psychological conceptualization. The use of diaries as an intervention to aid psychological recovery in intensive care patients has been examined in 11 studies, including two randomized controlled trials. Inconsistencies exist in sample characteristics, study outcomes, study methods, and the diary intervention itself, limiting the amount of comparison that is possible between studies. Measurement of the impact of the diary intervention on patient outcomes has been limited in both scope and time frame. Furthermore, an underpinning conceptualization or rationale for diaries as an intervention has not been articulated or tested. Given these significant limitations, although findings tend to be positive, implementation as routine clinical practice should not occur until a body of evidence is developed to inform methodological considerations and confirm proposed benefits.
\end{abstract}

\footnotetext{
* Correspondence: l.aitken@griffith.edu.au

${ }^{1}$ NHMRC Centre of Research Excellence in Nursing, Health Practice Innovation - Griffith Health Institute, Griffith University, Kessels Road, Nathan, QLD 4111, Australia

${ }^{2}$ Intensive Care Unit, Princess Alexandra Hospital, Ipswich Road, Woolloongabba, QLD 4102, Australia

Full list of author information is available at the end of the article
}

\section{Introduction}

Critical illness and injury present multiple challenges to patients and their families. For patients, critical illness presents an immediate threat to survival and physical well-being. Patients and their families also need to address the psychological impact of physical illness, the experience of often painful interventions, the impact of ongoing treatment and rehabilitation, and exposure to the intensive care environment.

The combination of critical illness, its treatment, and the ICU results in sleep deprivation, exhaustion, and sedative and opiate use and their withdrawal, all of which may affect patients' short- and long-term psychological health. Patients recovering from critical illness frequently suffer from memory loss, nightmares, and delusional memories [1] that may continue for some time after discharge. Some patients develop symptoms of anxiety, depression, and post-traumatic stress that may be either acute or chronic [2]. The use of diaries for ICU patients is emerging as a putative tool to 'fill the memory gaps' and promote psychological recovery. In this review, we critically analyze the available literature regarding the use of diaries for ICU patients to determine the impact of diaries on ICU patient recovery.

\section{What is a patient diary?}

Diversity of practice in structure, content, and process elements regarding the use of diaries for ICU patients exists. Although there is a range of models used to create diaries for ICU patients, they are generally completed on behalf of the patient with the aim of providing a record of events which occurred throughout his or her ICU admission. There is also variation in the primary purpose of initiating a diary. Goals include giving time back to the patient, assisting the patient to work through their ICU experience, and providing individual or improved quality care $[3,4]$. The use of diaries has been conceptualized as a therapeutic instrument, an act of caring, an expression of empathy, or a hybrid of any of these [5]. 
The majority of reported diary usage has been within Europe, particularly Scandinavia [3,5-8] and the UK [2,8-11], although diaries are rarely reported as standard practice. Between $40 \%$ and $76 \%$ of ICUs in Denmark, Norway, and Sweden have reported using diaries $[3,5,6]$, but usage in other countries is relatively unknown. Few guidelines regarding the use of diaries exist. Generally, patients who were sedated or ventilated (or both) or admitted to the ICU for a significant period of time were the main recipients of diaries $[3,4,6,10]$, although reported variations include the availability and personal interest of the nurses [5] and diaries not being provided to patients who either were awake and orientated or had severe cerebral damage, dementia, or developmental delay [6].

Diaries are generally written prospectively and addressed personally to the patient and generally contain a summary of the reason for admission, a narrative of daily activities, and a final note on transfer from the ICU [4]. There is little empirical evidence or theoretical foundation informing the content and timing of patient diaries. Some ICUs focused on the provision of medical information $[7,11,12]$ and included technical jargon, whereas other units focused on social and environmental events with a light overview of health status using non-medical language $[3,4]$. The separation of treatment-related information from the main patient diary has been advocated [4]. Inconsistency in the number of diary entries also exists. Egerod and Bagger [13] noted that, in the diaries of the four patients they interviewed, one diary had 11 entries, two had four entries, and one had three entries. The authors suggested that the potential impact of some diaries may be compromised given the brevity of the record; its brevity may raise more questions than it answers and potentially result in poorer psychological outcomes post-ICU.

Diary entries were made predominantly by the bedside ICU nurse, and family members were encouraged to write in some diaries $[10,11]$. In one report, family members were encouraged to keep a separate diary because their points of view were considered important to themselves as well as to the patient [6]. There have been limited reports of non-nursing staff contributing to diaries for ICU patients $[3,6,7]$.

Photographs have been included as a contextual clue to encourage memory recall, to help in the replacement of inaccurate memories, and to assist in the understanding of the trajectory of the ICU stay and as a tool in a person's acceptance of events $[4,10]$. Inclusion of individual patient photographs raises concerns regarding privacy, consent, and relevance [5]. Reports of specific criteria for the use of photographs include using generic photographs to minimize the impact [5] or excluding sensitive photographs such as patients with a disfigured face [3]. The two methods may produce different outcomes in a similar way to that found when using personal scripts of traumatic experiences rather than presenting generalized images about trauma. Scripts describing the personal experience of trauma tended to provoke trauma memories with more emotional content [14].

The timing and format for the presentation of the diary also varied; diaries were provided to patients between ICU discharge $[4,15]$ and up to 2 months postICU $[2,10,12,16,17]$. No rationale and no empirical or theoretical support for the timing of diary provision was offered by any authors. Minimal detail is available about the process or level of support offered at the time of providing the diary to the patient $[10,15,18]$, despite its preparatory importance to the delivery of the primary intervention. Practice differed from simply putting the diaries on the end of the bed when transferring a patient out of the ICU with no discussion undertaken $[3,4,7]$ to delivering a coordinated system of follow-up and support for the patients and families, answering questions about the content and counseling the patient if required $[2,17]$. An intermediate practice of following up patients to ensure that they understood the contents via a conversation either in person or over the phone was used in the large randomized controlled trial (RCT) [8]. A return visit to the ICU, with an opportunity to ask questions of staff, was also described in one study [10]. Providing the diary to the patient with little or no support or guidance is not consistent with the empirical literature on post-trauma psychological early intervention [19] or with theories of cognitive behavioral early-intervention approaches post-trauma [20]. These variations in structure, content, and processes related to the use of diaries for ICU patients emphasize the lack of an underpinning psychological conceptualization or rationale for the use of diaries vide infra.

\section{Literature search strategy}

Studies that focused on the evaluation of a diary compiled for an ICU patient, including diaries compiled by staff or family members or both, were included in the review. Ovid MEDLINE (1950 to February 2013), Ovid EMBASE (1980 to February 2013), EBSCOhost CINAHL (1982 to February 2013), Cochrane Central Register of Controlled Trials (April 2013 issue), and PsycINFO (1950 to February 2013) were searched by one member of the author team (AJU). A MeSH (Medical Subject Headings) term for 'patient diaries' is not available, so a combination of the phrases of 'patient diary' or 'patient diaries' was used in conjunction with the MeSH term of 'intensive care units'. Searches were performed without year or language restrictions but were limited to human studies. From the database searches, 43 titles were 
identified, 13 were removed as duplicates, with $30 \mathrm{ab}-$ stracts reviewed. Eight studies were excluded as they did not examine patient diaries, and 11 were excluded as the authors reported only descriptive information regarding the extent, application, and content of patient diaries, in comparison with an evaluation of their effectiveness. Reference lists of relevant papers were checked for additional studies.

At least two members of the author team (including at least one member with clinical intensive care expertise and one member with psychological or psychiatric expertise) critically appraised each study. All study appraisals were circulated to all team members, with themes developed through email and teleconference communication on the basis of the strengths and limitations identified in the appraisal process.

\section{Effect of diaries on recovery}

The use of diaries as an intervention to aid psychological recovery after the ICU has been the focus of 11 studies (Table 1). The majority of these studies were descriptive, and only two were RCTs $[2,8]$. Inconsistencies in sample characteristics, study outcomes, and study methods limit interpretation of this body of evidence.

\section{Sample characteristics}

Diaries have been labeled as being for 'ICU patients'; however, participants in the efficacy studies have varied and have included either ICU patients or both patients and family members; no studies focused solely on family members. Given this confusion, we have included all studies in which patients were a study participant, but we also noted the inclusion of, and considerations related to, family members. The potential benefit of diaries is likely to be different for each of these groups. Family members may feel a need for the patient to know how sick he or she had been, although the patient may not feel the same need. Alternatively, the patient may not have been interested in the diary but felt relieved 'because the diary could entertain his wife and spare him the involvement' [16]. The problem of differential effect is exacerbated by a lack of distinction between feedback from past patients or their family members [15].

The criteria used to identify potential study participants have often lacked objectivity (for example, expected prolonged illness [15] or when the patient and family could potentially benefit from a diary [9]). In contrast, few studies used objective criteria to identify patients [8], although these criteria may have led to the systematic exclusion of relevant subgroups of patients. Excluding patients who were too confused to provide informed consent [8] or patients with pre-existing posttraumatic stress disorder (PTSD) or other psychological issues $[2,8]$ may have excluded those with the potential to benefit most from receiving a diary post-ICU.

\section{Outcomes}

The majority of studies examining the impact of ICU patient diaries have used open-ended questions of either individuals or groups, generally in an unstructured or semi-structured interview $[9,12,16-18]$ or questionnaire $[15,21,22]$. Standardized questionnaires or clinical diagnostic interviews of psychological outcome were seldom used, although there were exceptions $[2,8,23,24]$. When used, assessments were used in a variety of ways, including in person, via telephone [23], or via mail [24]. It is difficult, therefore, to identify the nature and extent of the impact other than whether patients were satisfied and felt they were a useful memory aid. This lack of standardized outcome assessment is a major omission if the diaries are being used to maintain psychological resilience or to promote psychological recovery.

Interviews have most commonly been conducted 6 to 12 months after ICU discharge [9,13,16,18]; one study extended to 18 months [12] and one study did not specify the time frame [21]. It was not always apparent who conducted the interviews, although in some cases it appears to have been the person responsible for delivering follow-up services, including the diary $[9,12]$. The questionnaires that were used were often developed locally, with limited [21] or no reports of validation [15,22]. The remaining three studies used previously validated instruments to assess health-related quality of life (Medical Outcomes Study 36-item short-form) [24], anxiety and depression (Hospital Anxiety and Depression Scale) [2], PTSD Diagnostic Scale and Post-Traumatic Stress Symptoms [8], and memory recall of ICU (ICU Memory Tool) [8].

With the exception of the time frame of Backman and colleagues, who measured health-related quality of life at $6,12,24$, and 36 months [24], time frames for outcome measurement were short. Specifically, Knowles and Tarrier [2] measured anxiety and depression when the diary was provided to the patient approximately 1 month after ICU discharge and again 3 weeks later. In this small group of 36 patients, both anxiety and depression decreased from 1 to 3 months in the diary group, and there was no change in the control group (Table 1). Jones and colleagues [8] measured post-traumatic stress 3 months after discharge from the ICU (that is, approximately 2 months after receiving the diary); however, the PostTraumatic Stress Disorder Diagnostic Scale (PDS) was not administered through self-report as designed [25] and validated; rather, it was adapted as an invalidated interview [8]. In this large cohort of patients, there was a difference found between rates of probable PTSD diagnosis as assessed by the PDS in the intervention group 
Table 1 Studies examining diary use for intensive care unit survivors

\begin{tabular}{|c|c|c|c|c|}
\hline $\begin{array}{l}\text { Authors } \\
\text { (year), } \\
\text { country }\end{array}$ & Study design & Population & Intervention; evaluation & Findings \\
\hline \multirow{2}{*}{$\begin{array}{l}\text { Backman } \\
\text { and Walther } \\
\text { [15] (2001), } \\
\text { Sweden }\end{array}$} & \multirow[t]{2}{*}{ Observational } & \multirow{2}{*}{$\begin{array}{l}51 \text { patients and } 10 \text { of } \\
\text { their relatives from a } \\
\text { single ICU }\end{array}$} & \multirow{2}{*}{$\begin{array}{l}\text { Diary given to patients } 2 \text { to } 4 \text { weeks after } \\
\text { ICU discharge; questionnaire mailed } \\
6 \text { months later }\end{array}$} & $\begin{array}{l}\text { - 40/41 patients and all relatives had read } \\
\text { diary; } 26 \text { diaries read more than } 10 \text { times. }\end{array}$ \\
\hline & & & & $\begin{array}{l}\text {-39/51 questionnaires had comments: } 13 \\
\text { graded neutral, } 11 \text { positive, } 15 \text { very positive. }\end{array}$ \\
\hline $\begin{array}{l}\text { Backman et } \\
\text { al. [24] } \\
\text { (2010), } \\
\text { Sweden }\end{array}$ & $\begin{array}{l}\text { Prospective cohort } \\
\text { study with } \\
\text { retrospective } \\
\text { reference group }\end{array}$ & $\begin{array}{l}40 \text { patients from three } \\
\text { ICUs }\end{array}$ & $\begin{array}{l}\text { Diary and photos to patient } 2 \text { to } 8 \text { weeks } \\
\text { after ICU discharge, questions answered by } \\
\text { ICU team; health-related quality of life } \\
\text { (HRQLL) assessed } 6,12,24 \text {, and } 36 \text { months } \\
\text { after hospital discharge }\end{array}$ & $\begin{array}{l}\text { Diary plus follow-up visit associated with } \\
\text { higher HRQOL. }\end{array}$ \\
\hline
\end{tabular}

Bergbom et Qualitative, al. [21] explorative

(1999),

Sweden

Combe [9] Qualitative, (2005), UK explorative
10 patients and four of their relatives from a single ICU

25 patients from a single ICU
Engstrom et Qualitative, al. [18] explorative (2008),

Sweden
Egerod and Bagger [13] (2010), Denmark
Qualitative, explorative Nine patients from a
single ICU

Four patients from a single ICU
Diary prepared by ICU staff, given to patient on ICU discharge, follow-up 1 week later to answer questions; survey to patients after hospital discharge

Diary \pm photos prepared in ICU by staff and relatives, given to patients approximately 6 weeks after discharge; unclear when and how evaluation was obtained
- Seven (70\%) patients stated that the diary helped them recollect events/people from ICU and come to terms with illness/injury. - Three (75\%) relatives reported diary had helped them return to everyday life and to understand the seriousness of the patient's illness/injury.

- Photos assisted as a 'reality check' when setting goals for recovery.

- Diaries helped resolve differences in experience between patients and families.

- Enabled patients to 'move on' to normal life.

- Mixed feelings by family members of bereaved patients regarding seeing photos of loved one.

Diary \pm photos prepared in ICU by staff and relatives, given to patients after ICU discharge; unstructured interviews $\sim 1$ year later.

- Main theme - 'touching a tender wound', with four categories: being afraid and being deeply touched, appreciating close relatives' notes, a feeling of unreality and gaining coherence.

- Strong feelings and reactions when reading it for the first time, ranging from joy to sorrow and amazement. Some reported reading the diary felt like going through it all again, being thrust back into that difficult time.

- Diary was not a dependable source of information, because significant events were 'glossed over' or neglected.

relatives, given to patients 1 month (intervention) or 3 months (control) after ICU discharge; focus group evaluation.
Egerod et al. Qualitative, [16] (2011), explorative Denmark
Six individual patients and 13 pairs (patient and their relative) from two ICUs
Diary and photo prepared by ICU staff and relatives, given to patients 1 month (intervention) or 3 months (control) after ICU discharge with a 'handover' from ICU staff; focus group and semi-structured interview 6 to 12 months after ICU discharge
- Participants agreed that the diary did not stimulate memory or enhance recall but filled the memory gaps and enabled reconstruction of their story.

- Participants disagreed on the best time to hand over diary as some patients were ready sooner than others.

- The handover interview, the diary, and the photographs were all seen as a source of information; although the diary did not reestablish memory per se, it helped fill in memory gaps.

- Some reported the initial reading of the diary was unpleasant, especially when scheduled 'prematurely'.

- Information contained in the diary was considered incomplete, but it did provide a 


$\begin{array}{lll}\text { Jones et al. RCT } & 352 \text { patients from } 12 & \begin{array}{l}\text { Diary and photo prepared by ICU staff and } \\ \text { relatives, given to patients } 1 \text { month after }\end{array} \\ \text { [8] (2010), six } & \text { ICUs } & \text { ICU discharge; assessment of PTSD (using } \\ \text { European } & \text { PTSS-14) and memory recall of ICU (using } \\ \text { countries } & \text { ICUMT) at } 1 \text { and } 3 \text { months post-ICU. PDS } \\ & \text { administered only } 3 \text { months post-ICU }\end{array}$

Knowles and RCT

Tarrier [2]

(2009), UK
36 patients from a single ICU

20 patients from a single ICU
Diary prepared by ICU staff; given to patient 1 month after ICU discharge by ICU nurse consultant, with questions answered; anxiety and depression (using HADS) assessed at 1 and 3 months after ICU discharge catalyst for discussion with relatives and health-care workers.

- Fewer probable cases of PTSD using PDS at 3 months in intervention versus control group (3\% versus $13 \%, P=0.02$ ), but no pre-intervention (1 month) evaluation of probable PTSD was undertaken to allow assessment of incidence.

- No difference was found between patients in the control and intervention groups on the PTSS-14 at 1 and 3 months, and no change was found from 1 and 3 months in either group, suggesting no effect of the intervention.

- Patients in the intervention group with a PTSS-14 scoring above a cutoff of 45 at 1 month had a significant reduction in the PTSS-14 symptoms score at 3 months compared with patients with the same range of scores in the control group (Fisher's exact test $P=0.04$ ).

- Recall of delusional memories reduced equally in both groups.

- A significant decrease in both anxiety $(P$ $<0.05)$ and depression $(P<0.005)$ from

1 month to 3 months was identified in the intervention group, with no differences between the two time points in the control group.

- There were fewer anxious patients in the intervention group at 3 months $(P<0.05)$, but no significant difference in depression.

Diary and photos prepared by ICU staff and • 11 (55\%) found diary distressing first time relatives given to patients prior to hospital they looked at it, with comments including discharge; survey to all patients who received diary in previous 2 years 'realizing how ill I had been', 'shocking to know how bad things were', 'photo distressing', 'comments seemed to refer to me as a child'.

- All respondents thought it helped make sense of what had happened.

- Two (10\%) felt unhappy with diary content (friends wrote inappropriate things, photos harrowing, wanted 'happy ending' photo, gaps in content, ended too soon).

Diary and photos prepared by ICU staff given to patient after ICU discharge, conversations and visits back to the ICU; indepth interviews 6 and 18 months after ICU discharge
- Diary was interpreted as incorporating an aspect of gift giving, displaying caring, strongly emotional and individualistic.

- Diary helped discover meaning and connections in patients' experiences.

- Texts and pictures confirmed the visitors' presence and loving care as well as helped prompt memories of bodily sensation and realism regarding rehabilitation and recovery.

HADS, Hospital Anxiety and Depression Scale; ICUMT, Intensive Care Unit Memory Tool; PDS, Post-Traumatic Stress Disorder Diagnostic Scale; PTSD, post-traumatic stress disorder; PTSS-14, Post-Traumatic Stress Syndrome 14-Question Inventory; RCT, randomized controlled trial.

compared with the control group at 3 months, but given that there had been no baseline assessment using the PDS to confirm similarity of the two groups, it is not possible to draw reliable conclusions from this finding.
Furthermore, using the Post-Traumatic Stress Syndrome 14-Question Inventory, post-trauma stress symptoms did not change over time and were similar in the two groups at 3 months, providing no evidence of reduction 
in PTSD symptoms in response to the diary intervention (Table 1). There is evidence to suggest that patients' psychological health after the ICU continues to be problematic beyond 3 months, suggesting that this follow-up timeline is insufficient [26-28].

\section{General methodological considerations}

Only two RCTs $[2,8]$ and one cohort study with a retrospective reference group [24] have been conducted in this area, whereas other studies were cohort studies. Sample sizes have been small; there were 4 [13] to 19 [16] patients in the qualitative studies and 25 patients [9] to 352 patients (in the single large study) [8] in the quantitative studies. Samples have usually been from one center and highly selective, and as few as $10 \%$ of the patients in each ICU received the diary intervention $[2,8,15,24]$. Retention rates were high in the two RCTs $[2,8], 25 \%$ in the cohort study with retrospective reference group [24], and generally much lower in the small cohort studies. Potential issues of sample and attrition bias make generalizability difficult.

As discussed earlier, the characteristics and dose of the intervention, including number of diary entries, content, detail and style of each entry, and frequency of diary reading, have also been highly variable. Content may be added to the diaries by different members of the healthcare team or the family or both, the number of entries in the diary may have been quite small (for example, 3 or 4), and the number of times the patient read the diary limited. These limitations raise the question of the 'dose' of the intervention and whether it is theoretically plausible or empirically supportable that a small dose intervention may actually influence outcomes. We know that patients have limited recall of factual events related to the ICU [1], and the diary may offer a means of filling in such memories. However, patients themselves do not contribute to the diaries and therefore there are questions of whose memories these diaries represent.

\section{Theoretical underpinnings}

Any new intervention must be based on an underpinning conceptualization or rationale. A fundamental difficulty for diaries is that their use is not targeted to the prevention or treatment of a specific psychological disorder but to addressing gaps in memory between islets of recall.

Various psychological reactions after ICU admission have been described and PTSD has been prominent among them. For some individuals, these psychological reactions may be associated with events that precede the ICU admission; these could include a traumatic injury, a life-threating illness, a health-care intervention prior to the ICU admission, or events and factors unrelated to the admission (for example, pre-morbid life stressors).
These other events do not necessarily diminish the potential impact of the ICU admission. Instead, they may potentiate any post-ICU reactions.

Much research on autobiographical memory for trauma has been completed and is beyond the scope of this paper (for review, see [29]). Experimental evidence suggests that high levels of stress could result in highly accessible intrusive images and fragmented, incomplete autobiographical memories. This is echoed in ICU experiences. In both adult and pediatric ICU survivors, a relationship between post-traumatic stress symptoms and less factual recall or recall of delusional memories has been reported [30,31].

Core symptoms of PTSD involve memory (for example, amnesia and intrusive phenomena, both of which would be considered potential targets for the provision of information through diaries). No one model or conceptualization has gained primacy in this area, but cognitive models of the etiology of PTSD have attempted to explain the memory abnormalities seen. Of note, there is substantial overlap between three prominent recent models related to memory function: the emotional processing model [32], the dual representational model [33], and the integrative cognitive model [34]. A comparative analysis has noted that each of these explains factors relating to memory function and its potential abnormalities and processes post-trauma [35]. Any one of these models could form the basis of an intervention for PTSD after ICU admission. Simplistically, if trying to prevent PTSD and other post-ICU psychological disorder, diaries as an intervention should be shared with only the subset of ICU patients viewed as being more atrisk for poor psychological outcomes post-ICU [19]. The subset of ICU patients who might benefit from this intervention has not yet been determined, nor has the means of feasibly and reliably determining an 'at risk' individual in a post-ICU setting; however, the trial by Jones and colleagues [8] does suggest that 'at risk' individuals are the only ones to benefit from diary-based intervention.

\section{Clinical application}

The wish to intervene post-ICU reflects the humane desire to help, but it is not always better to do something rather than nothing. As noted elsewhere, psychological interventions post-trauma are rarely neutral and may inhibit recovery [36]. It is also likely that what constitutes 'helpful' diary information will vary among ICU patients, who are a heterogeneous group similar only in that their illness was critical. It is likely that only a proportion of ICU patients require this intervention, and the nature of diaries, their content, the timing of the intervention, and who should be targeted need to be defined empirically. Diaries may be preventative, encourage resilience, or 
promote recovery, but it is not yet known how effective they may be, what elements or approach may be most effective, which patients will benefit, and for whom they may have an adverse effect. Post-trauma, chronic psychological maladjustment is not the rule with many individuals recovering their functional equilibrium quickly after brief initial distress [37]; $60 \%$ to $70 \%$ of patients do not have a psychological disorder 12 months post-ICU. Diaries are unlikely to reduce the risk of PTSD for all and may increase the risk for some. The controversy and debate regarding psychological debriefing should inform all early interventions post-ICU (for example, [38]), with diaries needing to be targeted at those needing them [39], and an awareness that psychological interventions are rarely neutral. Acceptability and satisfaction with diaries should be viewed with caution as acceptability does not equate to effectiveness.

Diaries for patients may, with further research, be shown to be very effective. However, the provision of diaries to ICU patients and its study are in their infancy, with more questions raised than answers. Any change to usual practice should demand empirical findings to underpin the proposed new intervention. It can be argued that any intervention that promotes more accurate and complete autobiographical recall with greater understanding of the trauma experience to counterbalance delusional memories could promote better psychological outcomes post-ICU, although not all patients will want it and this should be respected and allowed for. The assumption regarding diaries is that the patient needs to know what happened. Properly presented, the provision of information may well be helpful for the patient [40,41], but it may also confront or limit their previously effective adaptive strategies, confuse the patient with what they remembered and what they have been told, or emphasize elements they would otherwise have filtered out. Ordinary forgetting should not be underestimated as a useful human skill and may reflect that an event is not particularly memorable or may depend on the emotional state or triggers for the memory [35].

The style of writing in patient diaries also requires consideration. Component analyses of diaries for patients are required to determine what aspects are effective. Should patients be advised how to use the supplied diaries? Should the diaries be written in the third person or in a phased approach (that is, past, present, and future)? Should they be written in a pragmatic or hopeful manner? No description in the current available literature has addressed these vital considerations for effective use of a narrative approach to target either failures of registration of experience or forgotten, traumatic, or dissociated memories. It is likely that ICU nurses would require training and guidelines in this specialist approach, highlighted by the difficulties reported by some nurses in authorship [4].
Although the issue has not yet been discussed in the literature, it is unknown whether the current approach for diaries needs to be modified to assist patients admitted to the ICU with a history of trauma or psychological distress. As mentioned earlier, the effect of both of these may result in a cumulative effect on risk for poor psychological outcomes post-ICU.

\section{Conclusions}

The use of diaries across many countries, their characteristics, who receives them, and the methodology of the various studies show a degree of overlap but also significant variation, making comparisons challenging. There is a lack of clear, underpinning theory to support diary use, and many past authors have suggested a simple, pragmatic approach to the intervention. Simple solutions to complex problems can be successful but need careful consideration of diverse issues prior to widespread application.

Studies suffer from small numbers, selected samples, lack of clarity regarding the intervention delivered and in the method of assessment, the outcome measures chosen, and the length of follow-up. Although study findings tend to be positive, the methodological limitations suggest that implementation as routine clinical practice should not occur until a body of evidence is developed to inform methodological considerations and demonstrate efficacy.

\section{Abbreviations}

MeSH: Medical subject headings; PDS: Post-traumatic stress disorder diagnostic scale; PTSD: Post-traumatic stress disorder; RCT: Randomized controlled trial.

\section{Competing interests}

The authors declare that they have no competing interests.

\section{Author details}

${ }^{1}$ NHMRC Centre of Research Excellence in Nursing, Health Practice Innovation - Griffith Health Institute, Griffith University, Kessels Road, Nathan, QLD 4111, Australia. Intensive Care Unit, Princess Alexandra Hospital, Ipswich Road, Woolloongabba, QLD 4102, Australia. ${ }^{3}$ School of Nursing and Midwifery, University of Dundee, 11 Airlie Place, Dundee DD1 4HJ, UK. ${ }^{4}$ Multidisciplinary Adult Psychotherapy Service, Perth Royal Infirmary, Perth PH1 1NX, UK. ${ }^{5}$ School of Medicine, University of Queensland, Brisbane, QLD, 4029, Australia. ${ }^{6}$ School of Psychology, University of Queensland, Brisbane, QLD, 4029, Australia.

\section{Published: 18 December 2013}

\section{References}

1. Jones C, Griffiths R, Humphris G, Skirrow P: Memory, delusions and the development of acute post-traumatic stress disorder-related symptoms after intensive care. Crit Care Med 2001, 29:573-580.

2. Knowles R, Tarrier N: Evaluation of the effect of prospective patient diaries on emotional well-being in intensive care unit survivors: a randomized controlled trial. Crit Care Med 2009, 37:184-191.

3. Akerman E, Granberg-Axell A, Ersson A, Fridlund B, Bergbom I: Use and practice of patient diaries in Swedish intensive care units: a national survey. Nurs Crit Care 2010, 15:26-33. 
4. Egerod I, Schwartz-Nielsen K, Hansen G, Laerkner E: The extent and application of patient diaries in Danish ICUs in 2006. Nurs Crit Care 2007, 12:159-167.

5. Egerod I, Storli SL, Akerman E: Intensive care patient diaries in Scandinavia: a comparative study of emergence and evolution. Nurs Inq 2011, 18:235-246.

6. Gjengedal E, Storli SL, Jolme AN, Eskerud RS: An act of caring - patient diaries in Norwegian intensive care units. Nurs Crit Care 2010, 15:176-184.

7. Roulin MJ, Hurst S, Spirig R: Diaries written for ICU patients. Qual Health Res 2007, 17:893-901.

8. Jones C, Backman CG, Capuzzo M, Egerod I, Flaatten H, Granja C, Rylander C, Griffiths R, the RACHEL group: Intensive care diaries reduce new onset post traumatic stress disorder following critical illness: a randomised, controlled trial. Crit Care 2010, 14:168-178.

9. Combe D: The use of patient diaries in an intensive care unit. Nurs Crit Care 2005, 10:31-34.

10. Hale M, Parfitt L, Rich T: How diaries can improve the experience of intensive care patients. Nurs Manag (Harrow) 2010, 17:14-18

11. Thomas J, Bell E: Lost days - diaries for military intensive care patients. J R Nav Med Serv 2011, 97:11-15.

12. Storli SL, Lind R, Viotti I: Using diaries in intensive care: a method for following up patients. Connect 2003, 2:103-108.

13. Egerod I, Bagger C: Patients' experiences of intensive care diaries - a focus group study. Intensive Crit Care Nurs 2010, 26:278-287.

14. Hull AM: A review of neuroimaging findings in post-traumatic stress disorder. Br J Psychiatry 2002, 181:102-110.

15. Backman CG, Walther SM: Use of a personal diary written on the ICU during critical illness. Intensive Care Med 2001, 27:426-429.

16. Egerod I, Christensen D, Schwartz-Nielsen K, Agard AS: Constructing the illness narrative: a grounded theory exploring patients' and relatives use of intensive care diaries. Crit Care Med 2011, 39:1922-1928.

17. Egerod I, Christensen D: A comparative study of ICU patient diaries vs. hospital charts. Qual Health Res 2010, 20:1446-1456.

18. Engstrom A, Grip K, Hamren M: Experiences of intensive care unit diaries: 'touching a tender wound'. Nurs Crit Care 2008, 14:61-67.

19. Roberts NP, Kitchiner NJ, Kenardy J, Bisson Jl: Early psychological interventions to treat acute traumatic stress symptoms. Cochrane Database Syst Rev 2010, 3, CD007944.

20. Bryant RA, Harvey AG: Acute Stress Disorder: A Handbook of Theory, Assessment, and Treatment. Washington, DC: American Psychological Association; 2000.

21. Bergbom I, Svensson C, Berggren E, Kamsula M: Patients' and relatives' opinions and feelings about diaries kept by nurses in an intensive care unit: pilot study. Intensive Crit Care Nurs 1999, 15:185-191.

22. Robson W: An evaluation of patient diaries in intensive care. Connect 2008, 6:34-37.

23. Garrouste-Orgeas M, Coquet I, Périer A, Timsit JF, Pochard F, Lancrin F, Philippart F, Vesin A, Bruel C, Blel Y, Angeli S, Cousin N, Carlet J, Misset B: Impact of an ICU diary of family and patient psychological symptoms after an ICU stay. In European Society of Intensive Care Medicine. Barcelona, Spain: 23rd Annual Congress; 2010.

24. Backman CG, Orwelius L, Sjoberg F, Fredrikson M, Walther SM: Long-term effect of the ICU-diary concept on quality of life after critical illness. Acta Anaesthesiol Scand 2010, 54:736-743.

25. Foa EB, Cashman L, Jaycox L, Perry K: The validation of a self-report measure of posttraumatic stress disorder: The Posttraumatic Diagnostic Scale. Pychological Assessment 1997, 9:445-451.

26. Davydow DS, Gifford JM, Desai SV, Bienvenu OJ, Needham DM: Depression in general intensive care unit survivors: a systematic review. Intensive Care Med 2009, 35:796-809.

27. Aitken LM, Chaboyer W, Schuetz M, Joyce C, Macfarlane B: Health status of critically ill trauma patients. J Clin Nurs 2012, Dec 10 [Epub ahead of print].

28. Jackson JC, Hart RP, Gordon SM, Hopkins RO, Girard TD, Wesley E: Posttraumatic stress disorder and post-traumatic stress symptoms following critical illness in medical intensive care unit patients: assessing the magnitude of the problem. Crit Care 2007, 11:1-11.

29. Brewin CR: Autobiographical memory for trauma: update on four controversies. Memory 2007, 15:227-248.

30. Jones C, Backman C, Capuzzo M, Flaatten H, Rylander C, Griffiths RD: Precipitants of post-traumatic stress disorder following intensive care: a hypothesis generating study of diversity in care. Intensive Care Med 2007 33:978-985.

31. Dow BL, Kenardy J, Long DA, LeBrocque RM: Children's posttraumatic stress and the role of memory following admission to intensive care: a review. Clinical Psychologist 2012, 16:1-14.

32. Foa EB, Rothbaum BO: Treating the Trauma of Rape: Cognitive Behavioural Therapy for PTSD. New York: Guilford Press; 1998.

33. Brewin CR, Dalgleish $\mathrm{T}$, Joseph S: A dual representation theory of posttraumatic stress disorder. Psychol Rev 1996, 103:670-686.

34. Ehlers A, Clark DM: A cognitive model of posttraumatic stress disorder. Behav Res Ther 2000, 38:319-345.

35. Brewin CR, Holmes EA: Psychological theories of posttraumatic stress disorder. Clin Psychol Rev 2003, 23:339-376.

36. Hull AM: Psychological responses to critical care: dogs bark and other myths. Aust Crit Care 2012, 25:150-151.

37. Schnyder U, Moergeli H, Trentz O, Klaghofer R, Buddeberg C: Prediction of psychiatric morbidity in severely injured accident victims at one-year follow-up. Am J Respir Crit Care Med 2001, 164:653-656.

38. Kenardy J: The current status of psychological debriefing - it may do more harm than good. Br Med J 2000, 321:1032-1033.

39. Hull AM, Rattray J: Competing interests declared: early interventions and long-term psychological outcomes. Crit Care 2013, 17:111.

40. Thompson K, Le Brocque R, Olsson K: Information provision intervention for children and their parents following paediatric accidental injury. Eur Child Adolesc Psychiatry 2008, 17:316-325.

41. Cox C, Kenardy J, Hendrikz JK: A randomised controlled trial of a web-based early intervention for children and their parents following accidental injury. J Pediatr Psychol 2010, 35:581-592.

42. Storli SL, Lind R: The meaning of follow-up in intensive care: patients' perspective. Scand J Caring Sci 2009, 23:45-56.

doi:10.1186/cc13164

Cite this article as: Aitken et al:: The use of diaries in psychological recovery from intensive care. Critical Care 2013 17:253. 